\title{
The Impact of Observed Vegetation Changes on Land-Atmosphere Feedbacks During Drought
}

\author{
X. H. MENG \\ Climate Change Research Centre, University of New South Wales, Sydney, New South Wales, Australia, and Key \\ Laboratory of Land Surface Process and Climate Change in Cold and Arid Regions, Cold and Arid Regions \\ Environmental and Engineering Research Institute, Chinese Academy of Science, Lanzhou, China \\ J. P. Evans \\ Climate Change Research Centre, University of New South Wales, Sydney, New South Wales, Australia \\ M. F. MCCABE \\ Water Desalination and Reuse Centre, King Abdullah University of Science and Technology, Thuwal, Saudi Arabia
}

(Manuscript received 1 August 2013, in final form 17 November 2013)

\begin{abstract}
Moderate Resolution Imaging Spectroradiometer (MODIS)-derived vegetation fraction data were used to update the boundary conditions of the advanced research Weather Research and Forecasting (WRF) Model to assess the influence of realistic vegetation cover on climate simulations in southeast Australia for the period 2000-08. Results show that modeled air temperature was improved when MODIS data were incorporated, while precipitation changes little with only a small decrease in the bias. Air temperature changes in different seasons reflect the variability of vegetation cover well, while precipitation changes have a more complicated relationship to changes in vegetation fraction. Both MODIS and climatology-based simulation experiments capture the overall precipitation changes, indicating that precipitation is dominated by the large-scale circulation, with local vegetation changes contributing variations around these.

Simulated feedbacks between vegetation fraction, soil moisture, and drought over southeast Australia were also investigated. Results indicate that vegetation fraction changes lag precipitation reductions by $6-8$ months in nonarid regions. With the onset of the 2002 drought, a potential fast physical mechanism was found to play a positive role in the soil moisture-precipitation feedback, while a slow biological mechanism provides a negative feedback in the soil moisture-precipitation interaction on a longer time scale. That is, in the short term, a reduction in soil moisture leads to a reduction in the convective potential and, hence, precipitation, further reducing the soil moisture. If low levels of soil moisture persist long enough, reductions in vegetation cover and vigor occur, reducing the evapotranspiration and thus reducing the soil moisture decreases and dampening the fast physical feedback. Importantly, it was observed that these feedbacks are both space and time dependent.
\end{abstract}

\section{Introduction}

As an arid continent, Australia is vulnerable to drought, and relatively minor changes in the quantity and/or distribution of rainfall can have a dramatic effect on the environment (Ayliffe et al. 1998). Ramifications of the

Corresponding author address: X. H. Meng, Cold and Arid Regions Environmental and Engineering Research Institute, Chinese Academy of Science, 320 DongGang West Road, 730000 Lanzhou, Gansu, China.

E-mail: mxh@lzb.ac.cn recent decade-long drought (from 1997 to 2008) in southeast Australia were dire and included acute water shortages for rural and metropolitan areas, far-reaching ecosystem damage, and record agricultural losses (Ummenhofer et al. 2009; van Dijk et al. 2013). Bush fires were more numerous and intense and occurred earlier in the season during the drought (Sharples et al. 2010). Some changes in the climate and extreme weather events in Australia have been attributed to global warming, and climate projections indicate that dry conditions are likely to be more regular and severe than in previous years (Wei et al. 2011). 


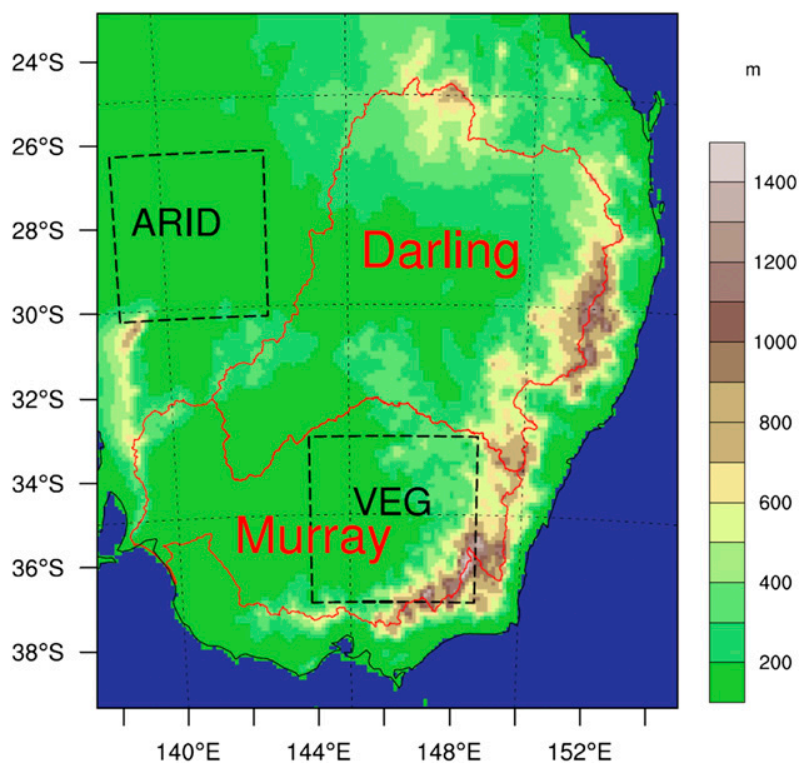

FIG. 1. Topography of southeast Australia from the WRF regional climate model terrain data (10-km-resolution domain). The Murray and Darling Basins are outlined in red. The black ARID and VEG boxes indicate focus regions for further analysis (ARID is a sparsely vegetated region; VEG is a region with dense vegetation).

Southeast Australia contains the Murray-Darling Basin (MDB) (Fig. 1), which supports $70 \%$ of the irrigated land and $40 \%$ of the agricultural product of the country. The 7-yr-averaged rainfall in the MDB for the period between October 2001 and September 2008 was close to the lowest since 1900 (Potter et al. 2010). The average recurrence interval of the mean rainfall during 1997-2006 in the southernmost parts of the MDB is up to $100 \mathrm{yr}$, whereas in mean annual runoff, it is up to $300 \mathrm{yr}$. Within the drought period from 1997 to 2008, 2002 and 2006 were the driest years, with negative precipitation anomalies of more than $8 \mathrm{~mm} \mathrm{month}{ }^{-1}$ in arid regions and $20 \mathrm{~mm} \mathrm{month}^{-1}$ in the more humid regions (Fig. 2).

Climate and meteorological variations have traditionally been considered as a set of forcing variables affecting land surface characteristics such as vegetation distribution, energy balance, and watershed hydrology, while the changes of land surface characteristics affect the atmosphere above it via fluxes of water, energy, and momentum — creating a feedback (Betts and Ball 1998; Betts 2009; Chen and Avissar 1994; Eltahir 1998). Many studies have sought to better understand the role of land-atmosphere interactions and its feedback with regional climate. Charney et al. (1975) hypothesized a negative albedo-precipitation feedback in which dry conditions favor reduced precipitation. Cook et al. (2006) investigated the effects of increased soil moisture on wet
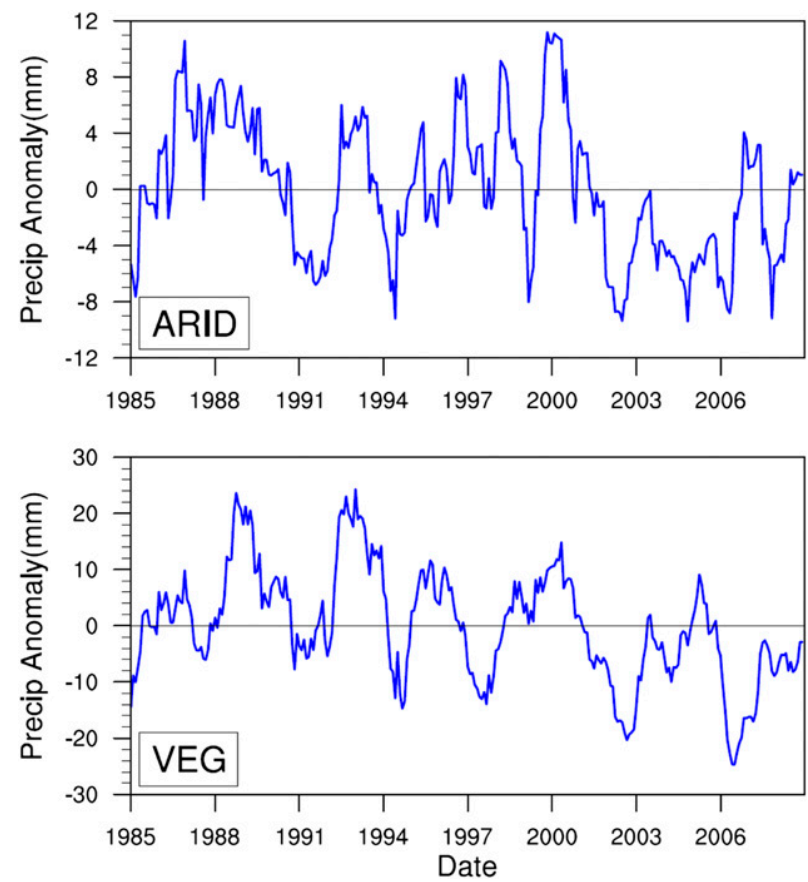

FIG. 2. Time series of precipitation anomalies observed from 1985 to 2008 (12-month running average) over the ARID and VEG regions.

season precipitation in southern Africa using the Community Climate System Model, version 3 (CCSM3), indicating that soil moisture may act as a negative feedback to precipitation in southern Africa. Meanwhile, positive feedbacks were found between global vegetation greenness and surface air temperature and precipitation from observations (Liu et al. 2006). These lines of investigation have revealed important interactions between soil moisture, vegetation, albedo, and climate. However, the importance of these feedbacks in different environments and the physical mechanisms that lead to them are difficult to constrain (Small and Kurc 2003) and are still less well documented in the Australian region (Evans et al. 2011).

While the large-scale circulations affecting the global patterns of drought have been discussed elsewhere $(\mathrm{Fu}$ et al. 2010; Risbey et al. 2009; Ummenhofer et al. 2011), one of the most challenging problems in land surfaceatmosphere feedback investigations is discriminating the physical mechanisms of land surface influences on the regional climate. Several mechanisms are proposed to characterize the coupling between land surface and local climate based on energy partitioning and water transfer (Betts and Ball 1998; Eltahir 1998; Findell and Eltahir 2003a; Xue et al. 2010). One important pathway is that land surface conditions affect the surfaceatmosphere fluxes of water and energy and the state of 
the planetary boundary layer (PBL) and, therefore, the likelihood for convective precipitation (Betts and Ball 1998; Eltahir 1998; Small and Kurc 2003; Meng et al. 2014). This mechanism is often addressed in two ways, both of which consider the variations of heat fluxes in the PBL. The first focuses on the influence caused by land-surface forcing from the surface into the PBL, while the second considers the impact of dry-air entrainment from the free atmosphere into the PBL. Recent studies using remote sensing observations have shown that these mechanisms are geographically specific, and the nature of their interactions depends on scale and regional context (Zaitchik et al. 2007).

Terrestrial ecosystems and climate influence one another on time scales ranging from seconds to millions of years (Pielke et al. 1998, 1991; Wang et al. 2006; Zeng and Neelin 2000). In a short-term process, the drying of the near-surface soil affects the partitioning of fluxes between sensible and latent heat, resulting in a warmer surface and deeper PBL height, providing a feedback with the atmosphere that varies over days to weeks. Seasonal interactions include feedbacks between decreased vegetation due to drought from spring to summer, reducing transpiration from the water-stressed vegetation, leading to more water preserved in the soil, and partially mitigating the drought condition (Pielke et al. 1998). As such, temporal-scale effects need to be considered if we are to improve our understanding of the behavior of land-atmosphere interaction and hydrologic systems.

The vegetation cover can be affected by interseasonal and interannual fluctuations in precipitation, and the viability of vegetation cover can substantially modulate the surface energy budget and the partitioning of available energy into sensible and latent heat fluxes (Matsui et al. 2005; Zaitchik et al. 2005). Owing to the importance of vegetation cover in hydrometeorological processes, temporally averaged vegetation climatologies may not be representative over the long term. This problem arises as a result of ongoing changes in land cover (Liu et al. 2013): for example, expanding agricultural regions, bushland encroachment, or areas that are affected by drought or other types of forcing on the land surface (Wang et al. 2006; Wang et al. 2012). As such, accurately representing vegetation fraction is key in providing representative regional climate modeling outcomes. Given the already stressed fraction of vegetation in southeast Australia during the extensive drought period, the influence of these land surface vegetation perturbations on precipitation is of particular interest.

The purpose of the work presented here is to 1) assess the impact of Moderate Resolution Imaging Spectroradiometer (MODIS)-based time-varying vegetation fraction on regional climate simulations over southeast Australia, 2) develop an improved understanding of interactions between vegetation cover and the atmosphere by tracking the change of vegetation during the prolonged drought, and 3) assess whether or not the vegetation cover-precipitation feedback exacerbated the drought in southeast Australia. Apart from providing a quantitative evaluation, the physical and biological feedback mechanisms operating on different time scales are also investigated and compared. To do this, the temporal and spatial characteristics of vegetation fraction from MODIS and the climatology of the standard Weather Research and Forecasting (WRF) Model are first analyzed. Then the WRF Model is set up to assess the influence of MODIS vegetation fraction on the regional climate by incorporating time-varying vegetation cover boundary conditions. Finally, the feedback between vegetation fraction and precipitation, including the possible mechanisms, are explored and discussed.

The paper is structured as follows. Section 2 briefly presents a description of the observational datasets of precipitation and temperature used in this work, the derivation of vegetation cover from two distinct datasets, and a comparison between these data. Section 3 describes the WRF Model and the experimental design. Section 4 evaluates the simulation results and assesses the impact of vegetation fraction on the regional climate. The vegetation fraction influence on the surface feedback to precipitation is presented and discussed in section 5, including evaluating the strength, scale, and distribution of these feedbacks in a severe drought. The final section summarizes the findings and identifies areas requiring future investigation.

\section{Data description and vegetation fraction variations}

\section{a. Precipitation and temperature data}

Gridded precipitation and air temperature products were used to evaluate the WRF Model outputs. These $0.05^{\circ}$-resolution products are interpolated from station measurements as part of the Australian Water Availability Project (AWAP) (Jones et al. 2009). The purpose of AWAP is to develop an operational system for estimating water-balance components, at scales ranging from $5 \mathrm{~km}$ to continental and over time periods from days to decades. These products have been widely used in a number of water balance studies of the MDB (Cai et al. 2009; Evans and McCabe 2010; Teng et al. 2012). In this work, the $0.05^{\circ}$-resolution products were interpolated to $10-\mathrm{km}$ resolution to enable direct comparison with the WRF Model results. 
TABLE 1. Comparisons of vegetation between WRF_MODIS and WRF_CTL.

\begin{tabular}{lll}
\hline \hline & \multicolumn{1}{c}{ WRF_CTL } & \multicolumn{1}{c}{ WRF_MODIS } \\
\hline $\begin{array}{l}\text { Sensor } \\
\text { Time period }\end{array}$ & AVHRR & Apr 1985-Dec 1987 and \\
& Jan 1989-Mar 1991 & 18 Feb 2000-Dec 2008 \\
& climatology & \\
Time step & Monthly & 8-day interval, \\
& & 16-day composite \\
$\begin{array}{c}\text { Spatial } \\
\text { resolution }\end{array}$ & $0.15^{\circ}$ & 500 m \\
\hline
\end{tabular}

\section{b. WRF default climatological vegetation fraction data}

The default vegetation fraction dataset used in the current WRF Model (version 3.1.1, referred to here as WRF_CTL vegetation fraction) was derived from Advanced Very High Resolution Radiometer (AVHRR)based monthly mean normalized difference vegetation index (NDVI) data between April 1985 and December 1987 and between January 1989 and March 1991 (Table 1). Details of the data can be found in the work of Gutman and Ignatov (1998).

\section{c. MODIS vegetation fraction data}

The MODIS-derived vegetation fraction data used to update the WRF lower boundary conditions is produced using the nadir bidirectional reflectance distribution function (BRDF) adjusted data from the combined Terra-Aqua MODIS product (MCD43A4.005). A linear unmixing methodology was used in the production (Guerschman et al. 2009). The methodology was originally developed for the Australian tropical savannas and evaluated using field measurements of grass curing in 10 sites, of which six are included in the tropical savannas and four are located in grasslands in the west and southeast of Australia (Guerschman et al. 2009). Then the method was applied to the whole Australian continent.

The product provides 8 -day, $500-\mathrm{m}$ resolution data that models reflectance values as if they were taken from nadir view (see Table 1). All of the vegetation fraction data can be downloaded from the MODIS Land Mosaics for Australia in the Water Resources Observation Network of Australia's Commonwealth Scientific and Industrial Research Organization (CSIRO).

Owing to the influence of clouds, missing values exist in time series of the MODIS-derived vegetation fraction data. Quality control was performed on the MODIS retrievals to remove outliers from the vegetation fraction data before further analysis. To do this, the following procedure was employed. At each pixel, the 9-yr vegetation fraction product with an 8-day interval (i.e.,
414 time steps) was denoted as $V$, while the value of each time step was denoted as $V_{x}$. If $\left|V_{x}-V_{x+1}\right|>10.0 \%$, five data points before $V_{x}$ and four data points after $V_{x+1}$ (a total of nine elements) were selected to make a new array $V_{1}$. The standard deviation (SD) and average (Avg) of $V_{1}$ was then calculated. If $\left|V_{x}-\mathrm{Avg}\right|>2.5 \times \mathrm{SD}$, $V_{x}$ was considered an outlier, removed from the time series, and replaced by a linear interpolation between the nearest two valid values. The approach was iterated until all obvious outliers were removed. To maintain consistency between the MODIS products and WRF defaults, the MODIS vegetation fraction was then reprojected to a Lambert conformal projection, resampled to 6-h intervals by using linear interpolation, and grid averaged to $10 \mathrm{~km}$ spatially to match the WRF simulation.

\section{d. Comparison of two vegetation fraction products}

Seasonal averages of the WRF vegetation climatology (WRF_CTL) and the quality-controlled MODIS vegetation fraction (WRF_MODIS) are shown in Fig. 3. Seasons are defined as austral summer [DecemberFebruary (DJF)], autumn [March-May (MAM)], winter [June-August (JJA)], and spring [September-November (SON)]. Both products show similar spatial patterns (i.e., high vegetation fraction over the east and south and low values over the northwest), with the densest vegetation along the southern coastline. The bottom panel of Fig. 3 shows the difference between MODIS and WRF default vegetation fraction. In general, MODIS vegetation fraction estimates are higher than those from WRF_CTL, except in the southeast during winter and, particularly, autumn.

To better address vegetation fraction changes over the different underlying surfaces, examples of sparsely (ARID) and densely (VEG) vegetated areas were selected (see Fig. 1), representing arid and more humid/ vegetated regions. Figure 4 shows time series of the two vegetation fraction datasets over these different regions. WRF_CTL shows a larger seasonal cycle, while MODIS data has both seasonal and interannual changes for both regions. MODIS data maintains larger values for the entire period over the ARID region. Vegetation fraction over the VEG region decreased from 2000 to 2003 (with a minimum in 2003) and then recovered somewhat from late 2003 until 2006, where they decreased throughout the year, reflecting the timing and location of the drought occurring throughout the region.

The differences between vegetation products can be attributed to both the acquisition time of the data used and differences in the sensors themselves. Since the MODIS data were collected throughout the actual simulation time period and with a higher resolution and more 


\section{WRF CTL}
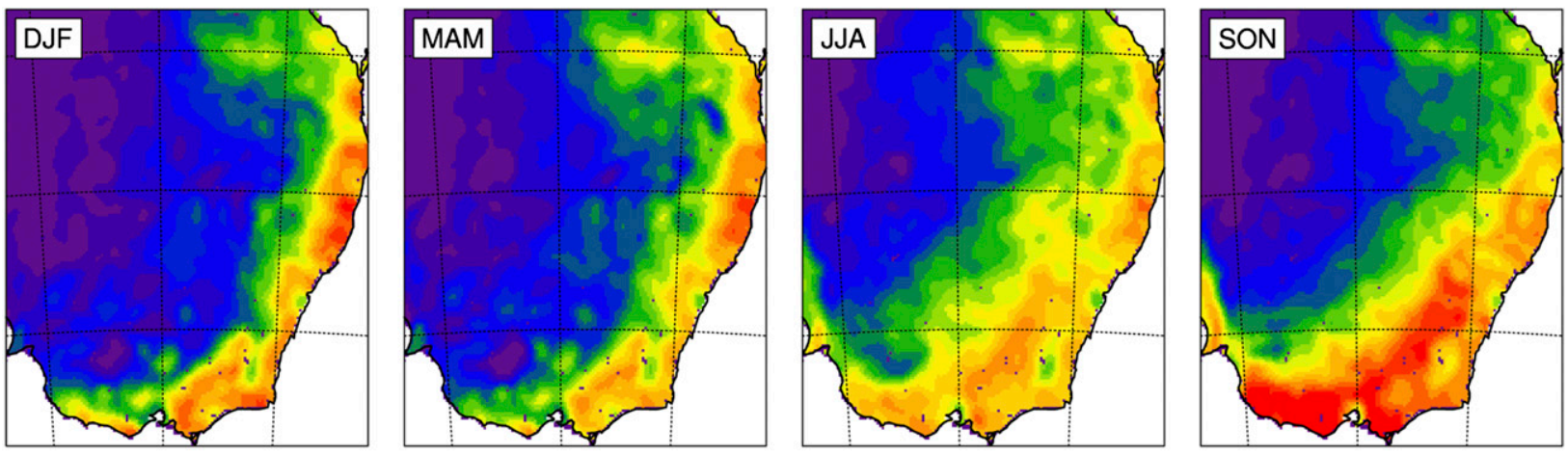

\section{MODIS}
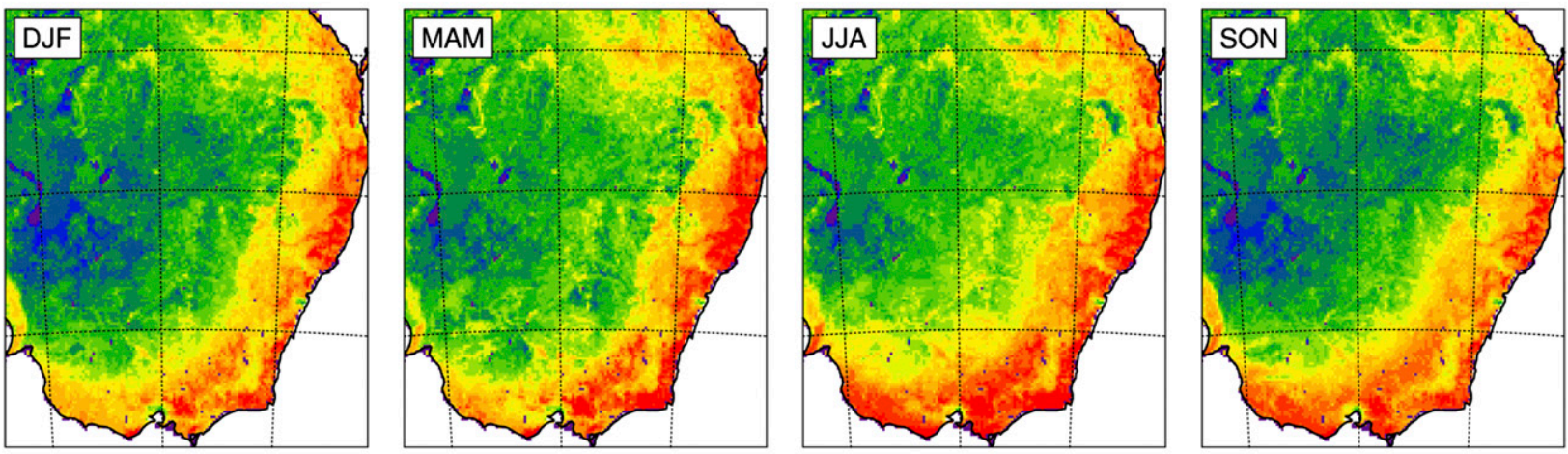

$\%$

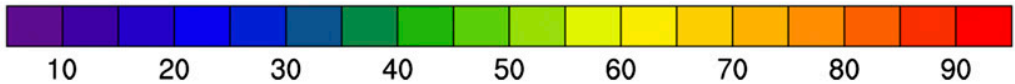

MODIS - WRF CTL
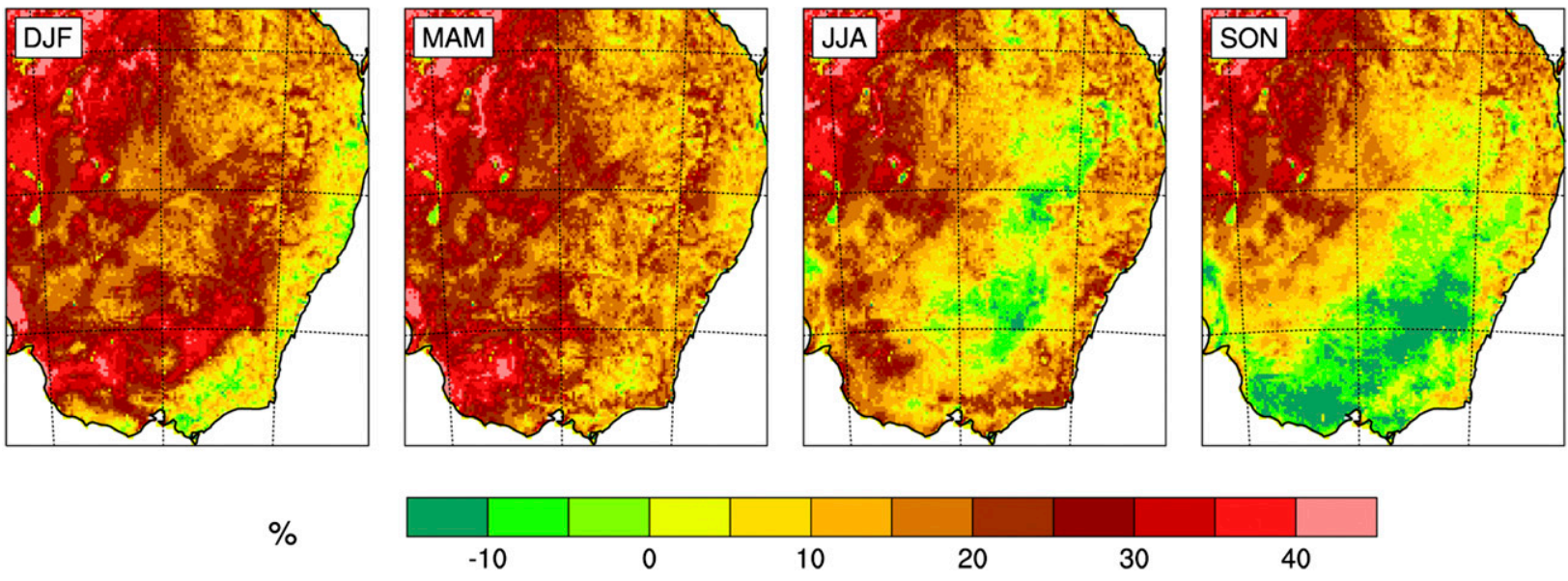

FIG. 3. Vegetation fraction from WRF default (WRF_CTL), MODIS, and differences between the two vegetation fraction products (MODIS minus WRF_CTL). 

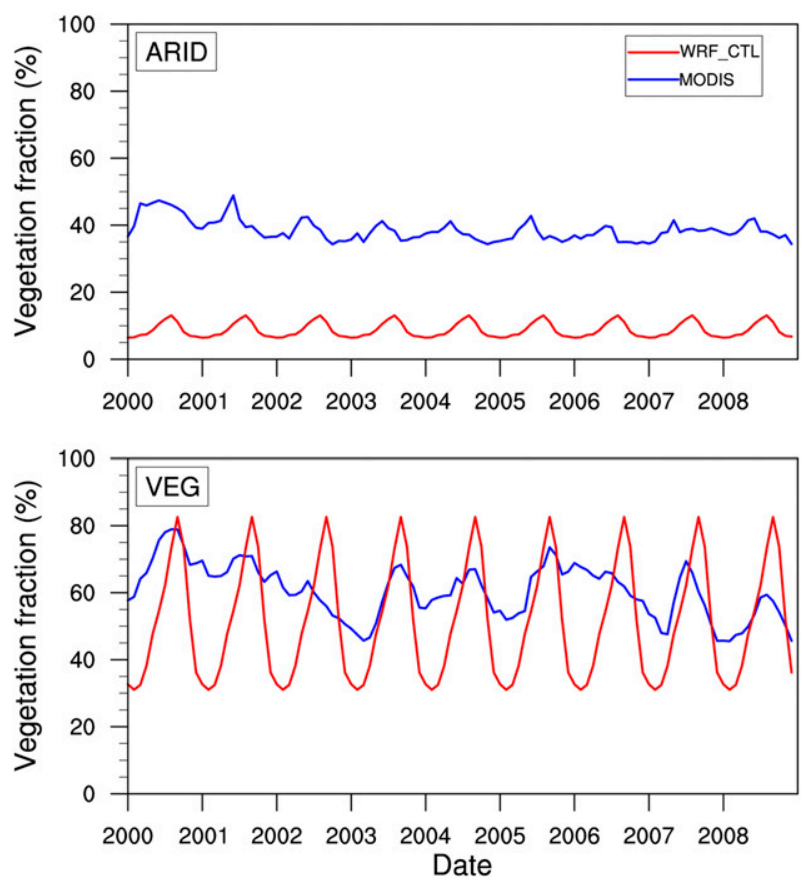

FIG. 4. Time series of vegetation fraction from the WRF_CTL and MODIS datasets over ARID and VEG grid boxes (see Fig. 1).

accurate sensor, thus considered to be a better representation of the actual fraction of the vegetation. The differences between the MODIS-based vegetation fraction and that based on the earlier AVHRR data is indicative of the errors involved in using the default WRF vegetation fraction dataset (which is standard "best" practice).

\section{WRF simulations}

The WRF Model is a widely used numerical model maintained at the National Center for Atmospheric Research (NCAR) in the United States. It has been developed through the collaborative efforts of a large number of institutions and individual researchers. WRF is a nonhydrostatic, terrain-following sigma coordinate model designed to simulate or predict mesoscale and regional-scale atmospheric circulation. WRF has been comprehensively evaluated across numerous investigations over southeast Australia and has been found to perform well (Evans and McCabe 2010; Evans et al. 2012; Evans and Westra 2012; Evans and McCabe 2013).

Version 3.1.1 (Skamarock et al. 2008) was applied in this study using the following physics schemes: the WRF single moment 5-class microphysics scheme, the Rapid Radiative Transfer Model (RRTM) longwave radiation scheme, the Dudhia shortwave radiation scheme, MoninObukhov surface layer similarity, the Noah land surface scheme, the Yonsei University boundary layer scheme, and the Kain-Fritsch cumulus physics scheme.

The model simulation uses 6-hourly boundary conditions from the National Centers for Environmental Prediction (NCEP)-NCAR reanalysis project (NNRP) with an outer $50-\mathrm{km}$ resolution nest and an inner $10-\mathrm{km}$ resolution nest centered at $32.7^{\circ} \mathrm{S}, 146.1^{\circ} \mathrm{E}$ that covers southeast Australia (Fig. 1). Figure 1 shows the topography of the inner domain (10-km resolution), detailing the large areas of relatively flat terrain throughout southeast Australia. Both nests used 30 vertical levels. The deep soil temperature was allowed to vary slowly with a 150-day lagged averaging period, while the atmospheric $\mathrm{CO}_{2}$ concentration changed monthly following measurements taken at Baring Head, New Zealand [see Evans and McCabe (2010) for further details of the model setup].

The WRF Model physics does not predict sea surface temperature, vegetation fraction, albedo, and sea ice. For long simulations, the model reads these timevarying data and continually updates the lower boundary condition. Since Evans and McCabe (2010) have successfully simulated regional climate from 1985 through 2008 over southeast Australia using the WRF Model, in this work WRF was restarted, based on their simulations from 2000 through 2008, to correspond with the period during which MODIS data is available. This allowed WRF more than 15 years (1985-99) to spin up the soil moisture states in a coupled environment. Two simulations were performed: one using the WRF default vegetation fraction (WRF_CTL) and the second using MODIS vegetation fraction (WRF_MODIS).

\section{Simulation results}

\section{a. Evaluation of the WRF simulations}

Precipitation and temperature outputs from the two simulation experiments were evaluated against AWAP observations. A series of statistics was calculated for the evaluation including bias, rms error (RMSE), spatial correlations of absolute values, and spatial correlations of anomalies from climatology (see Tables 2 and 3). Details of the statistics can be found in Evans and McCabe (2010).

Results show that simulations of monthly 2-m air temperature are closer to observations in WRF_MODIS. The biases of monthly average temperature are reduced by $0.37^{\circ}$ and $0.42^{\circ} \mathrm{C}$ for the Murray and Darling Basins, respectively, which is statistically significant at the 0.01 level according to a Student's $t$ test. In both cases the corresponding RMSEs are also smaller than for WRF_CTL (Tables 2 and 3). While little change is seen in the 
TABLE 2. Monthly statistics of temperature and precipitation between the simulations and AWAP over the Murray Basin.

\begin{tabular}{lcccc}
\hline \hline & \multicolumn{2}{c}{ Temperature (K) } & \multicolumn{2}{c}{ Precipitation (mm) } \\
\cline { 2 - 3 } & WRF_MODIS & WRF_CTL & WRF_MODIS & -5.48 \\
Bias & 0.49 & 0.86 & 11.27 & 11.27 \\
RMSE & 1.06 & 1.28 & 0.73 & 0.73 \\
Pattern correlation & 0.94 & 0.94 & 0.38 \\
Anomaly correlation & 0.32 & 0.24 & 0.39 \\
\hline
\end{tabular}

pattern correlation, the anomaly correlation is higher, indicating a better simulation of the interannual changes. For precipitation, the bias is smaller in both the Murray and Darling Basins while the other statistical measures remain essentially unchanged.

The spatial distribution of the differences in seasonal average air temperature and precipitation between model simulations and observations is displayed in Figs. 5 and 6. WRF_CTL overestimates air temperature in most of the MDB. WRF_MODIS also overestimates air temperature but does better than WRF_CTL. Both simulations show errors that are prevalent across the northeastern coastline. For precipitation (Fig. 6), the most substantial errors exist in the northeast of the MDB in both simulations in summer (DJF), when WRF_CTL produces a larger underestimate. In MAM, JJA, and SON the two simulations present only small differences. Both simulations also underestimate the precipitation in the mountainous region in the southeast, particularly in JJA, possibly a result of poor representation of terrain effects (Evans and McCabe 2013).

The time series of 2-m air temperature and precipitation for the two WRF simulations (WRF_CTL and WRF_MODIS) and observations (AWAP) (12-month running average) over the ARID and VEG region are shown in Fig. 7. Both of the WRF simulations can reproduce the variations of air temperature well, with the simulations of WRF_MODIS much closer to the AWAP observations most of the time. For the ARID region, WRF_CTL overestimates air temperature more than WRF_MODIS. For the VEG region, WRF_MODIS shows similar response to WRF_CTL for the peaks in late 2002, 2005, and 2007, while it reflects observations more closely than WRF_CTL at other times. Both WRF simulations can characterize the change of precipitation well, particularly for the drought in 2002 and 2006 for the VEG region. This might indicate that the precipitation in southeast Australia is dominated by large-scale circulations, which are common to both simulations through the boundary conditions, rather than from local-scale terrestrial responses.

\section{b. Influence of MODIS vegetation fraction on regional climate simulation}

Figure 8 shows differences in time series of climate variables between the two WRF simulations. In the ARID region there is a slight increase in the vegetation fraction, while in the VEG region there is a strong seasonality to the change, with MODIS exceeding CTL in austral summer and autumn and less than CTL during the rest of the year. These differences in vegetation fraction are reflected in changes observed in many other variables. Air temperature and surface temperature in both regions decrease with an increase in the vegetation fraction. Precipitation in the VEG region, particularly convective precipitation, was generally enhanced around summer, when the MODIS vegetation was higher. Similarly, a decrease is observed in late winter/early spring, when the MODIS vegetation fraction is lower.

For net radiation and surface fluxes, the higher MODIS vegetation fraction over the ARID region has substantially led to an overall higher net radiation, which is consistent with the investigation over a more arid region in the western United States (Case et al. 2014). A decrease in sensible heat flux and a corresponding increase in latent heat flux have been seen in 2000-01. Then, sensible heat flux tends to be slightly higher, whereas the latent heat flux varies near zero after equilibrium to the new vegetation dataset being established. In the VEG region, net radiation decreases most of the

TABLE 3. Monthly statistics of temperature and precipitation between the simulations and AWAP over the Darling Basin.

\begin{tabular}{lccrr}
\hline \hline & \multicolumn{2}{c}{ Temperature (K) } & \multicolumn{2}{c}{ Precipitation (mm) } \\
\cline { 2 - 3 } & WRF_MODIS & WRF_CTL & WRF_MODIS & WRF_CTL \\
\hline Bias & 0.81 & 1.23 & -1.91 & -2.83 \\
RMSE & 1.12 & 1.44 & 0.32 & 10.56 \\
Pattern correlation & 0.94 & 0.94 & 0.65 & 0.65 \\
Anomaly correlation & 0.40 & 0.33 & 0.42 & 0.42 \\
\hline
\end{tabular}


AWAP
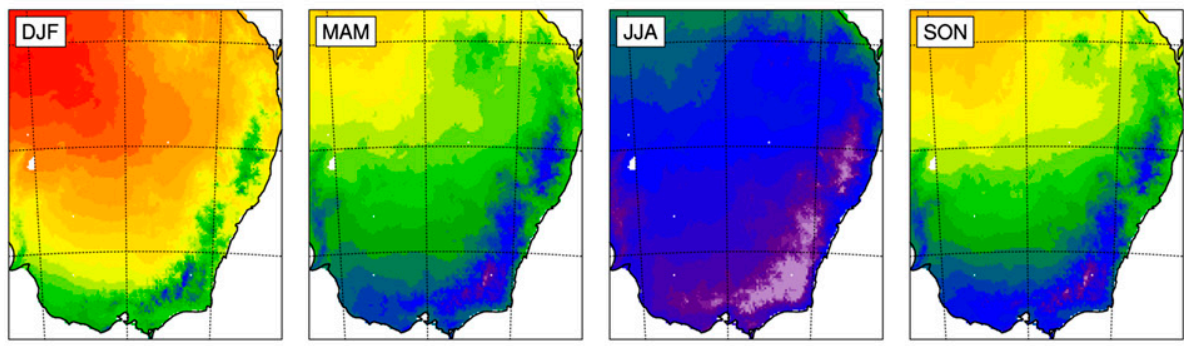

${ }^{\circ} \mathrm{C}$

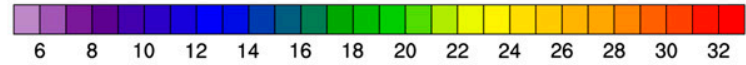

WRF_CTL - AWAP
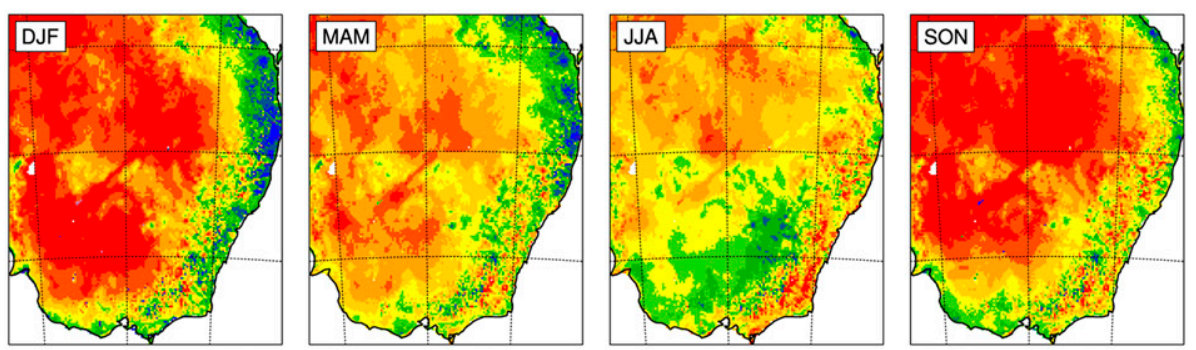

WRF_MODIS - AWAP
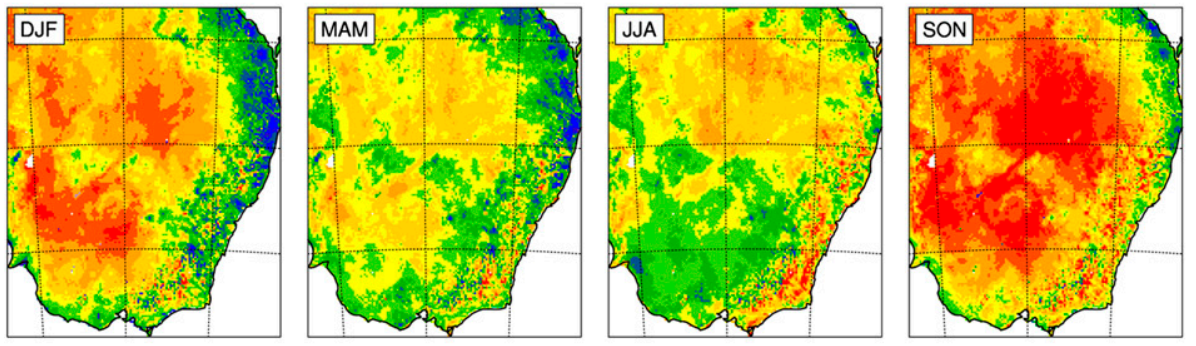

WRF_MODIS - WRF_CTL
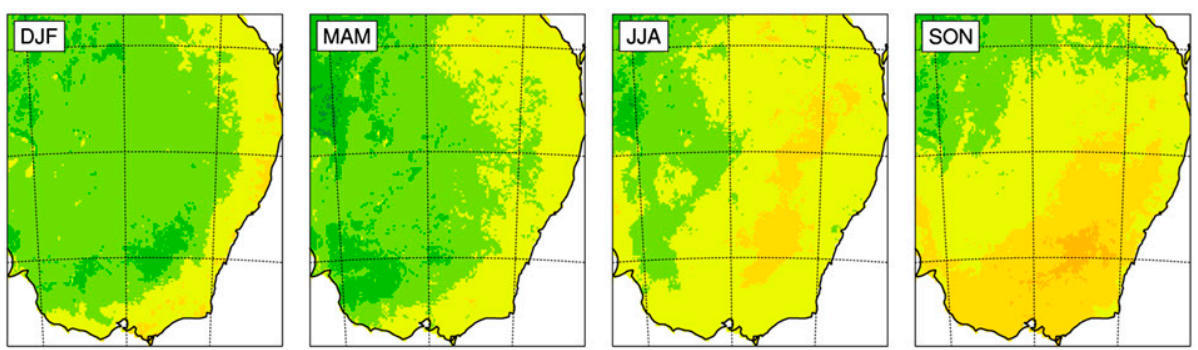

${ }^{\circ} \mathrm{C}$

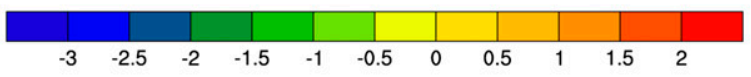

\section{WRF MODIS - AWAP}

FIG. 5. Distribution of 2-m air temperature from observations (AWAP), seasonal differences between the two simulations and observations (WRF_CTL minus AWAP and WRF_MODIS minus WRF_AWAP), and difference between the two simulations (WRF_MODIS minus WRF_CTL) averaged over $2000-08$. 
AWAP
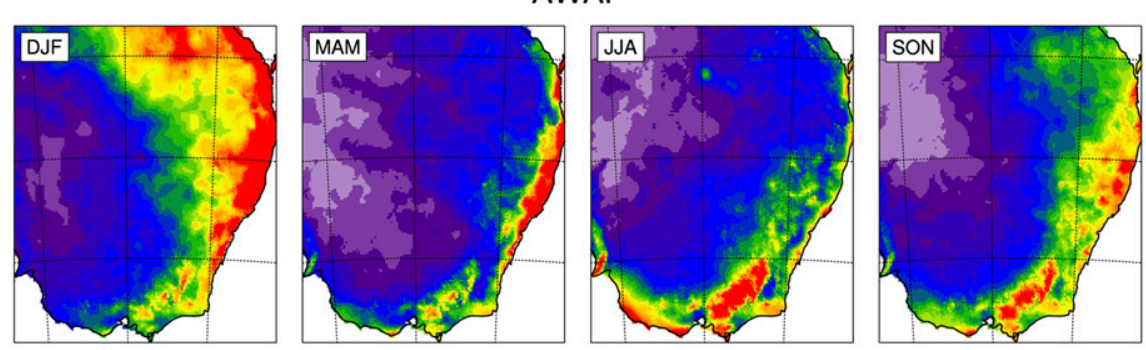

$\mathrm{mm} / \mathrm{month}$

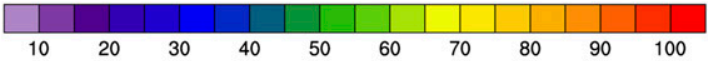

WRF CTL - AWAP
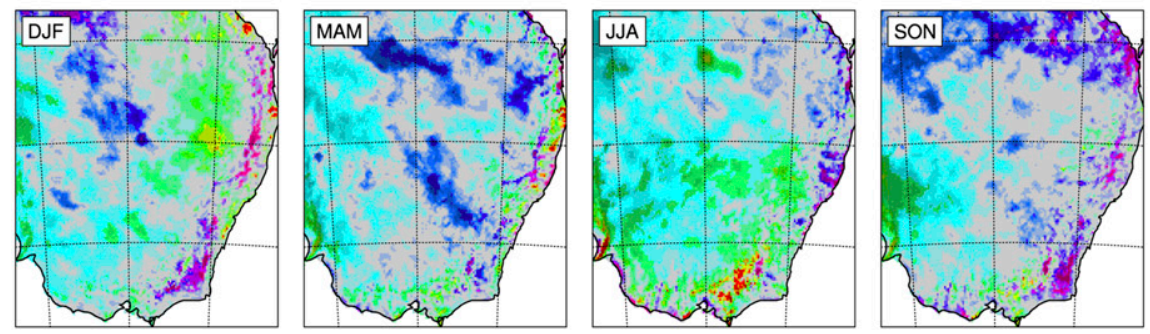

WRF_MODIS - AWAP
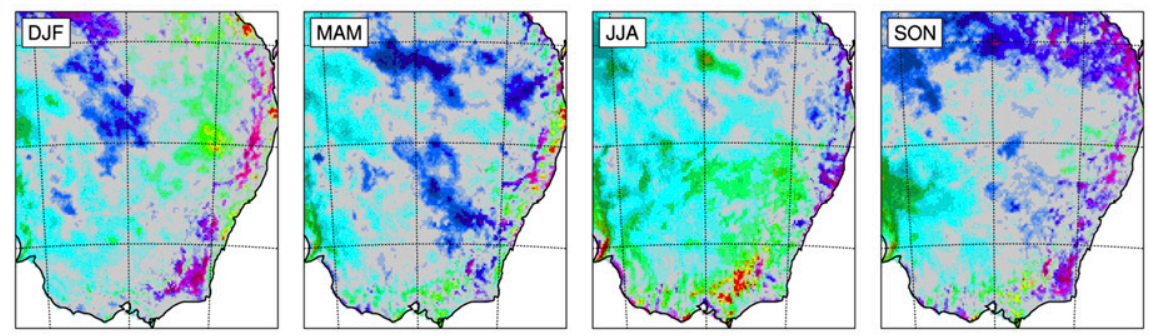

$\% \quad{ }_{10}^{60} \uparrow$

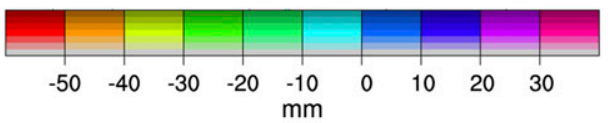

WRF_VEG - WRF_CTL
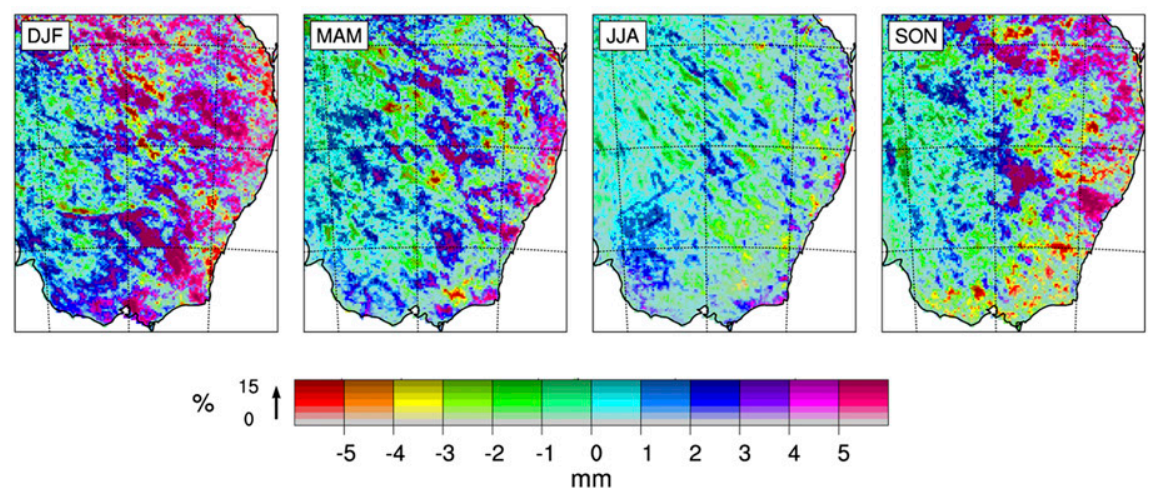

FIG. 6. Seasonal distribution of precipitation from observations (AWAP), seasonal differences between the two simulations and observations (WRF_CTL minus AWAP and WRF_MODIS minus WRF_AWAP), and difference between the two simulations (WRF_MODIS minus WRF_CTL) averaged over 2000-08 (top color bar indicates the difference mm month ${ }^{-1}$ per season; saturation indicates the difference in percent). 

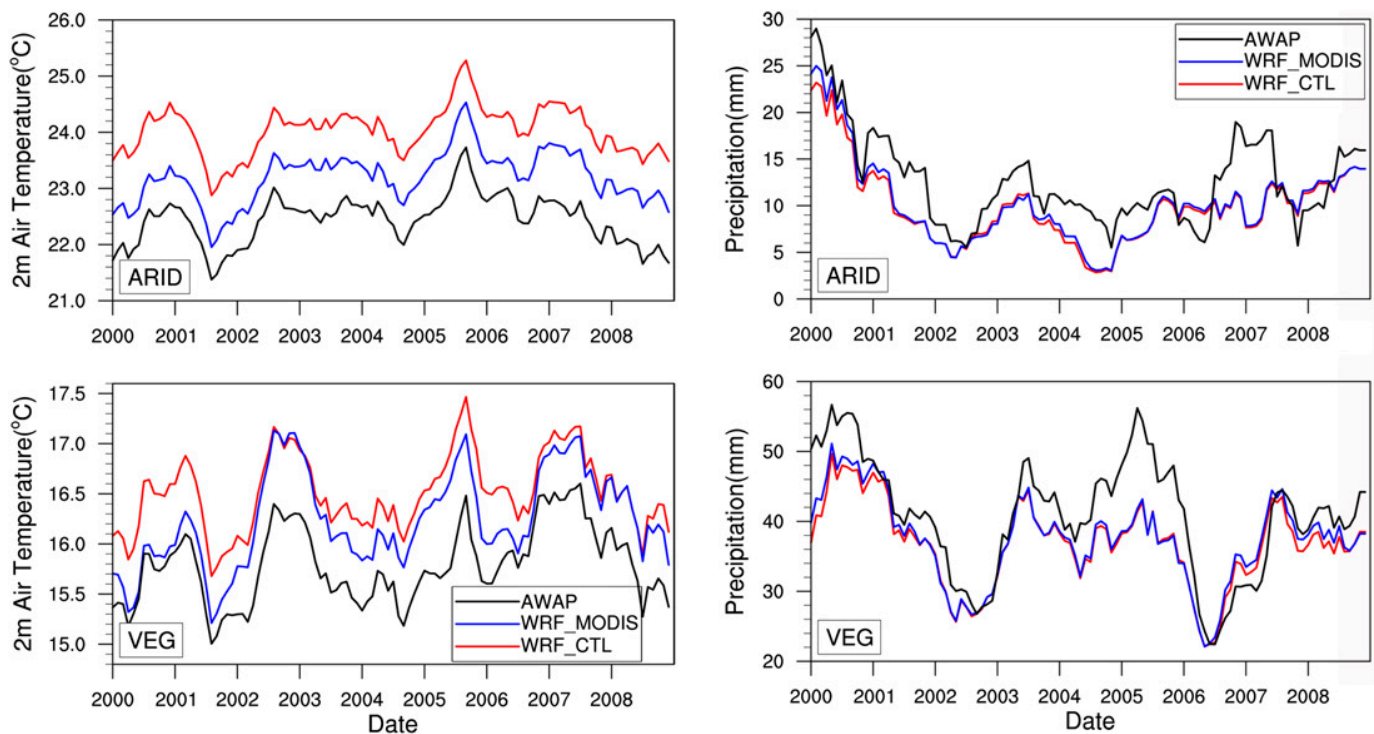

FIG. 7. Time series of 2-m air temperature and precipitation for the two WRF simulations (WRF_CTL and WRF_MODIS) and observations (AWAP) (12-month running average) over the ARID and VEG regions.

time compared to the WRF_CTL. Latent and sensible heat flux changes have the opposite response in the VEG region, with higher (lower) latent heat in DJF (JJA). Net radiation changes tend to show a decrease in summer, but little change at other times of the year.

Vegetation fraction has a strong influence on soil moisture in both shallow and deep layers. In response to change in vegetation products, the WRF_MODIS moisture in both 10- and 100-cm layers decreases in the ARID region, with the deeper layer having a much larger magnitude, consistent with the results found over arid regions in the western United States (Case et al. 2014). Soil moisture changes exhibit strong seasonal characteristics in the VEG region, but not in the ARID region owing to the seasonal change of vegetation fraction. For the VEG region, values in both soil moisture layers decrease. Here the largest decreases generally occur in austral autumn, while the smallest decreases (or increases) occur in austral spring, which follow the seasonal patterns of vegetation fraction in the VEG region.

The moist static energy (MSE) is a thermodynamic variable for studying precipitating convection. It describes the state of an air parcel, calculated by the combination of a parcel's kinetic energy, its potential energy, and the latent energy. Similar changes are seen in factors impacting precipitation. The MSE density (MSED) in the PBL, shown in Fig. 8, can be seen to generally increase in WRF_MODIS compared to WRF_CTL in the ARID region, especially in summer and autumn. In the VEG region, values during summer and autumn also generally increase, though the winter MSED decreases. In addition, maximum convective available potential energy
(MCAPE) increases during summer but has little change at other times of year. Together, these changes correspond reasonably well with changes in the convective precipitation.

\section{Land-atmosphere feedbacks}

\section{a. Response of vegetation fraction to drought}

As shown in Fig. 2, southeast Australia was experiencing drought during the period of the simulation experiments, particularly in the years 2002 and 2006. The drought led to both a direct and indirect influence on the hydrology and environment and was reflected by an observable response in the land surface vegetation fraction. Figure 9 shows the time series of a 12-month running average of vegetation fraction during 2000-08 versus precipitation anomaly for the same period, relative to the 1985-2008 average. In the ARID region, vegetation fraction follows the precipitation closely most of the time, while there is a clear lag in the VEG region. Investigating the lagged correlations between the precipitation and vegetation fraction reveals a $6-8$-month lag for vegetation fraction response to the precipitation anomaly in the VEG region. The minima of vegetation fraction occur in late 2002 and early 2008, corresponding to the drought peaks in 2002 and 2006, respectively. Although the negative precipitation anomaly decreased in 2007 and 2008 , it remained a negative anomaly, and the vegetation took a considerable time to respond. This difference in response time can be related to differences in the land cover type, with the ARID region being composed 
ARID
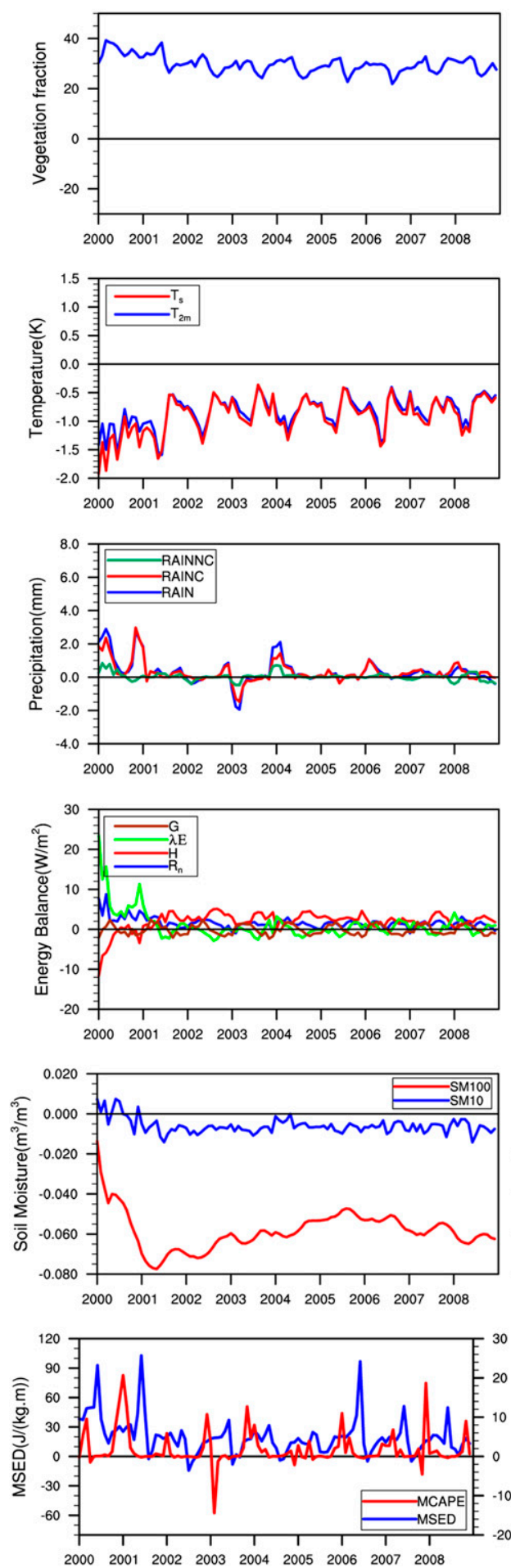

VEG
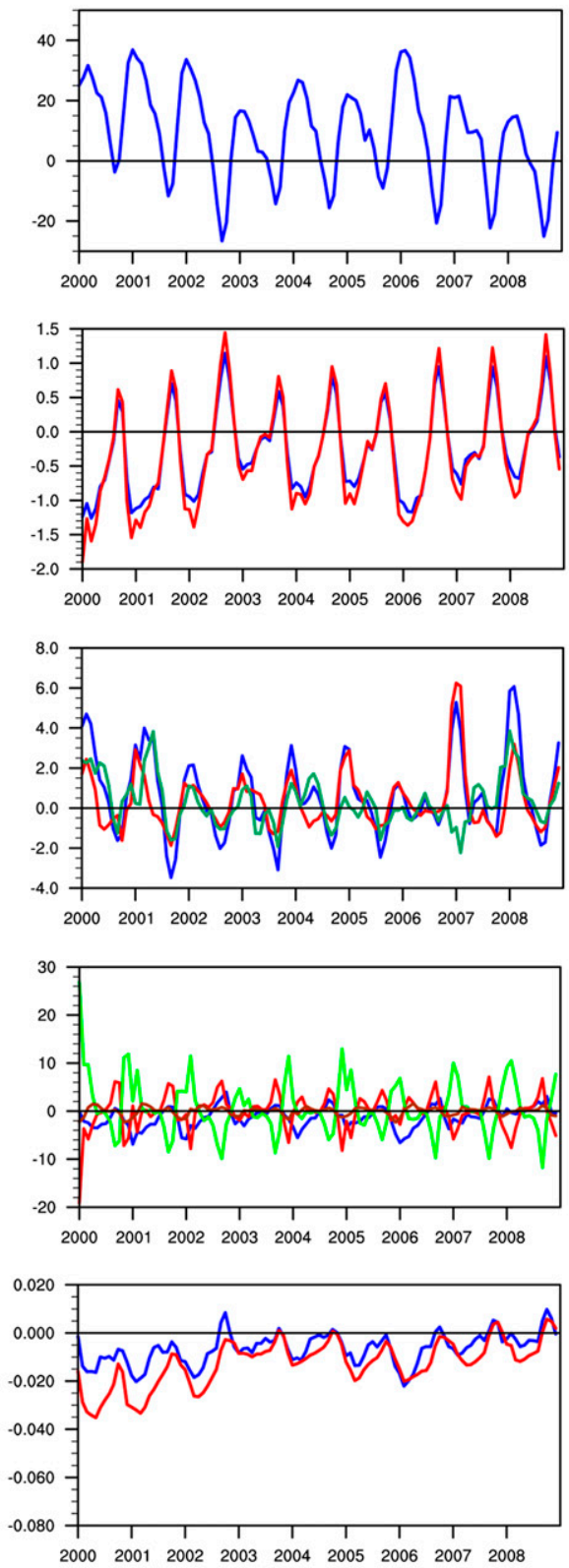

FIG. 8. Time series of the difference of variables between the two WRF simulations (WRF_MODIS minus WRF_CTL): $T_{2 \mathrm{~m}}$ and $T_{s}$ are 2-m air temperature and land surface temperature; RAIN, RAINC, and RAINNC are total precipitation, convective precipitation, and nonconvective precipitation, respectively; $R_{n}, \lambda E, H$, and $G$ are net radiation, latent heat, sensible heat, and ground heat flux, respectively; MSED is moist static energy density in PBL; MCAPE is the maximum convective available potential energy. 

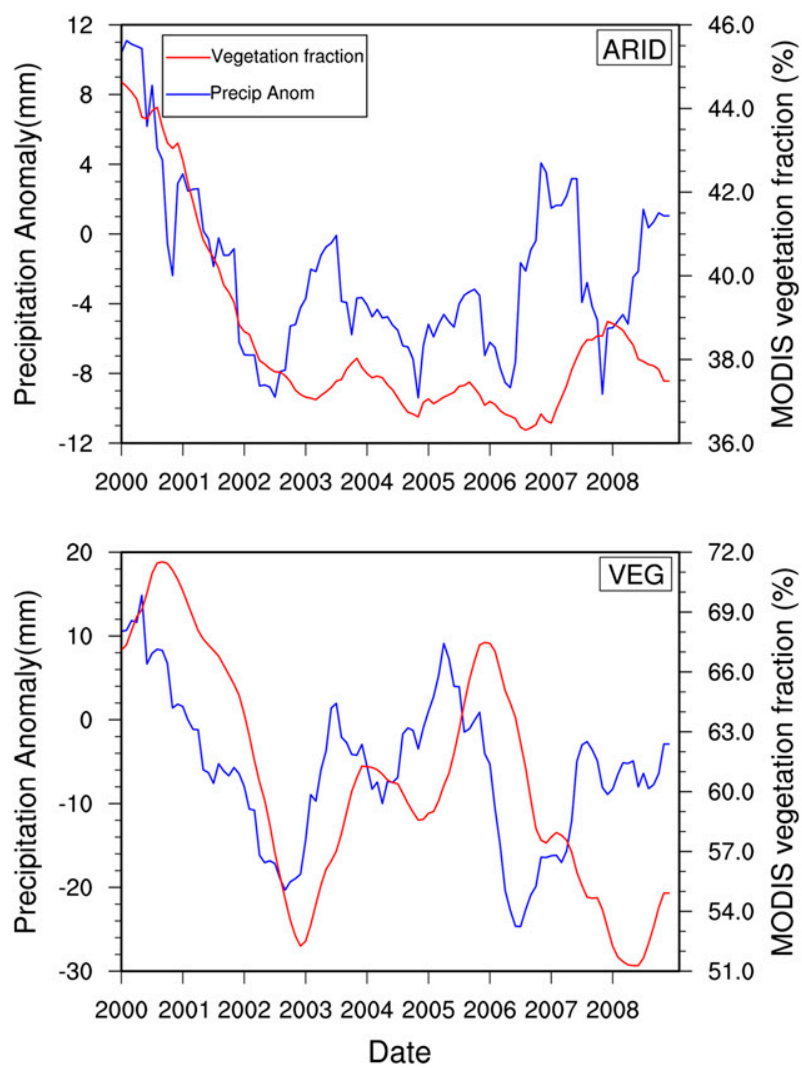

FIG. 9. Time series of MODIS vegetation fraction and precipitation anomalies (based on the time period from 1985 to 2008) from 2000 to 2008 (12-month running average) over the ARID and VEG regions.

largely by grasslands that respond quickly to precipitation, while the VEG region has significant forested areas that display a delayed response.

\section{b. Vegetation fraction influence on soil moisture-precipitation feedback}

Feedbacks between the land surface and the atmosphere have been the focus of recent investigations into the maintenance of extreme drought or flood conditions, as well as for more fundamental climatological research (Findell and Eltahir 2003b; Koster et al. 2006). Among all of the relevant parameters, soil moisture-precipitation feedback is considered most important, as it affects water, energy, and biogeochemical cycles, which involve a number of feedbacks at the local, regional, and global scale (Seneviratne et al. 2010). Soil moisture provides a positive feedback by affecting the moist static energy (MSE) and its density in the planetary boundary layer (PBL), which has been found to be an effective mechanism in previous studies (Eltahir 1998). During a drought, low soil moisture, as a proxy for water availability to vegetation, reduces the evaporative fraction $(\mathrm{EF})$ and

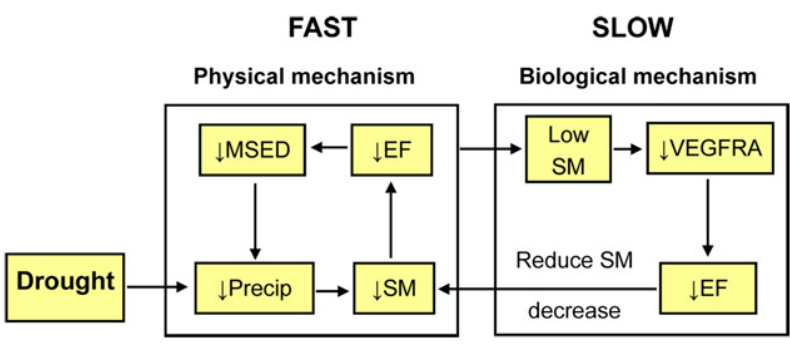

FIG. 10. Schematic of the land-atmosphere drought feedback mechanisms. Precip is precipitation, SM is soil moisture EF is evaporative fraction; MSED is moist static energy density in PBL; and VEGFRA is vegetation fraction.

thus affects the partitioning between latent and sensible heat flux. Decreasing soil moisture tends to decrease the net terrestrial radiation at the surface through increasing the land surface temperature and, hence, enhancement of upward emission of thermal terrestrial radiation. Thus, under drought conditions, net radiation may be decreased, leading to a reduction of total turbulent heat fluxes from the surface into the PBL (Eltahir 1998). At the same time, warming land surface temperatures associated with a relatively large sensible heat flux can lead to a deeper PBL height, which favors entrainment of warm, dry air from above the PBL (Betts and Ball 1998). With the influence of both the turbulent heat flux in the PBL and the PBL height, the density of MSE in the PBL decreases, leading to a reduction of precipitation and resulting in a positive feedback on drought, referred to here as a fast physical mechanism (see Fig. 10).

However, as the major pathway through which soil water is transferred into the atmosphere, vegetation generally promotes the land-atmosphere water exchange via transpiration in a biological process, changing the soil moisture conditions and affecting the land-atmosphere feedback. Compared to the direct soil moisture-precipitation feedback, vegetation feedbacks evolve slowly. Changes in vegetation fraction can lag changes in precipitation by more than 6 months (Fig. 9), after which vegetation changes start to play a role. Thus, in a drought, vegetation fraction is reduced because of persistently low soil moisture conditions, which leads to reduced transpiration via biological processes, preserving more water in the soil, which in turn slows the soil moisture reduction caused by the drought and provides a negative feedback. This mechanism is referred to as a slow biological mechanism (see Fig. 10).

Both the fast and slow mechanisms may exist in landatmosphere feedbacks during drought, according to theoretical analysis and previous studies. The drought in southeast Australia was most severe in 2002 and 2006. 
Here we focus the analysis on an examination of the drought onset phase in 2002 to see how land-atmosphere interactions respond to the most severe drought period.

Figure 11 presents maps of regions that experience coincident monthly decreases of precipitation, soil moisture, EF, and MSED in month by month variations between 2002 and 2003. These regions have conditions consistent with the hypothesized fast feedback pathway and are hence referred to as displaying the potential fast mechanism. The potential fast mechanism is least active in autumn (MAM). Murphy and Timbal (2008) show that the large rainfall decline in autumn is closely related to large-scale changes in circulation owing to the southern annular mode being in the positive phase and an increase in the intensity (and more southerly location) of the subtropical ridge at this time of year. The strong influence of these large-scale effects likely limit the impact of local feedbacks during autumn. In most cases, the active regions of the potential fast mechanism in WRF_CTL and WRF_MODIS overlap. This suggests that the potential fast feedback mechanism is not critically dependent on the vegetation fraction.

The long memory of soil moisture allows vegetation signals to persist for months. Such time-scale dependence further increases the complexity of interactions between vegetation and climate (Wang et al. 2006). Figure 12 shows maps of the potential slow mechanism, that is, regions that experience annual decreases of vegetation fraction and evaporative fraction (red and orange regions). It can be seen that most of southeast Australia is affected by this slow feedback throughout 2002 and then in the first half of 2003. This feedback ceases to be dominant, as the drought partially ended and vegetation recovered during July-December 2003.

Figure 12 also shows the locations where the potential fast mechanism is active at the same time. The potential fast and slow mechanisms are operating in coincident regions, indicated by orange. When the potential slow mechanism is active, the reduction in soil moisture and evaporative fraction is dampened, reducing the likelihood of a feedback through the MSED. Because of the relatively slow response of vegetation, the regions where the potential slow mechanism is active tend to persist through time, while the areas where the potential fast mechanism is active can change substantially on a monthly basis.

To quantify the impacts of the potential slow mechanism on the fast mechanism, Fig. 13 shows the monthly change of soil moisture, for a given initial soil moisture in WRF_MODIS, in areas where the potential fast mechanism alone is active and areas where both the fast and the slow mechanisms are active. While there is considerable overlap between the boxplots with and without the slow mechanism, inclusion of the slow mechanism has a clear tendency to reduce the subsequent soil moisture change. This tendency is dampened at very low soil moisture values owing to the soil moisture change being limited by the total available moisture. The tendency is strongest in midrange soil moisture values between 0.2 and $0.32 \mathrm{~m}^{3} \mathrm{~m}^{-3}$. According to a Student's $t$ test, the mean change in soil moisture is statistically significantly different at the $95 \%$ level for all initial soil moisture bins except the highest value bin. This indicates that the slow biological mechanism has a significant impact in all but the wettest regions in which it is active. As an overall average, the slow biological mechanism reduced the change in soil moisture occurring in regions where the fast physical mechanism was active by almost $22 \%$, thus reducing the positive feedback between soil moisture and precipitation.

\section{Discussion and conclusions}

In this study, MODIS-derived vegetation fraction data were used to update the boundary conditions of the advanced research WRF Model to assess the influence of observed vegetation fraction on local to regional scale climate modeling over southeast Australia. The vegetation fraction from MODIS showed increases over most of the region relative to the WRF default vegetation fraction, especially in the west of the MDB, and slight decreases in the southern part of the Murray Basin in JJA and SON. Simulation results show that by incorporating the MODIS-based vegetation dataset, air temperature is improved relative to an in situ-based observation dataset. Precipitation is also improved, though less so than for temperature. Both WRF_CTL and WRF_MODIS simulations capture the overall precipitation changes, indicating that precipitation is dominated by large-scale circulations. Corresponding with the precipitation anomalies, MODIS vegetation fraction shows different responses for different regions in southeast Australia. In the arid region, temporal patterns in MODIS vegetation fraction follow the precipitation at almost the same time, while variations are lagged by $6-8$ months in the more humid, heavily vegetated region.

Considering the influence of MODIS vegetation fraction on the climate simulation, energy and water partitioning due to the change of vegetation fraction was used to explain the impacts of land surface conditions on local climate over southeast Australia. Air temperature change in different seasons reflects the variability of vegetation fraction very well, while precipitation change has a more complicated relationship with the change in vegetation fraction and matches the changes of MSED and MCAPE, especially in the more heavily vegetated region. 

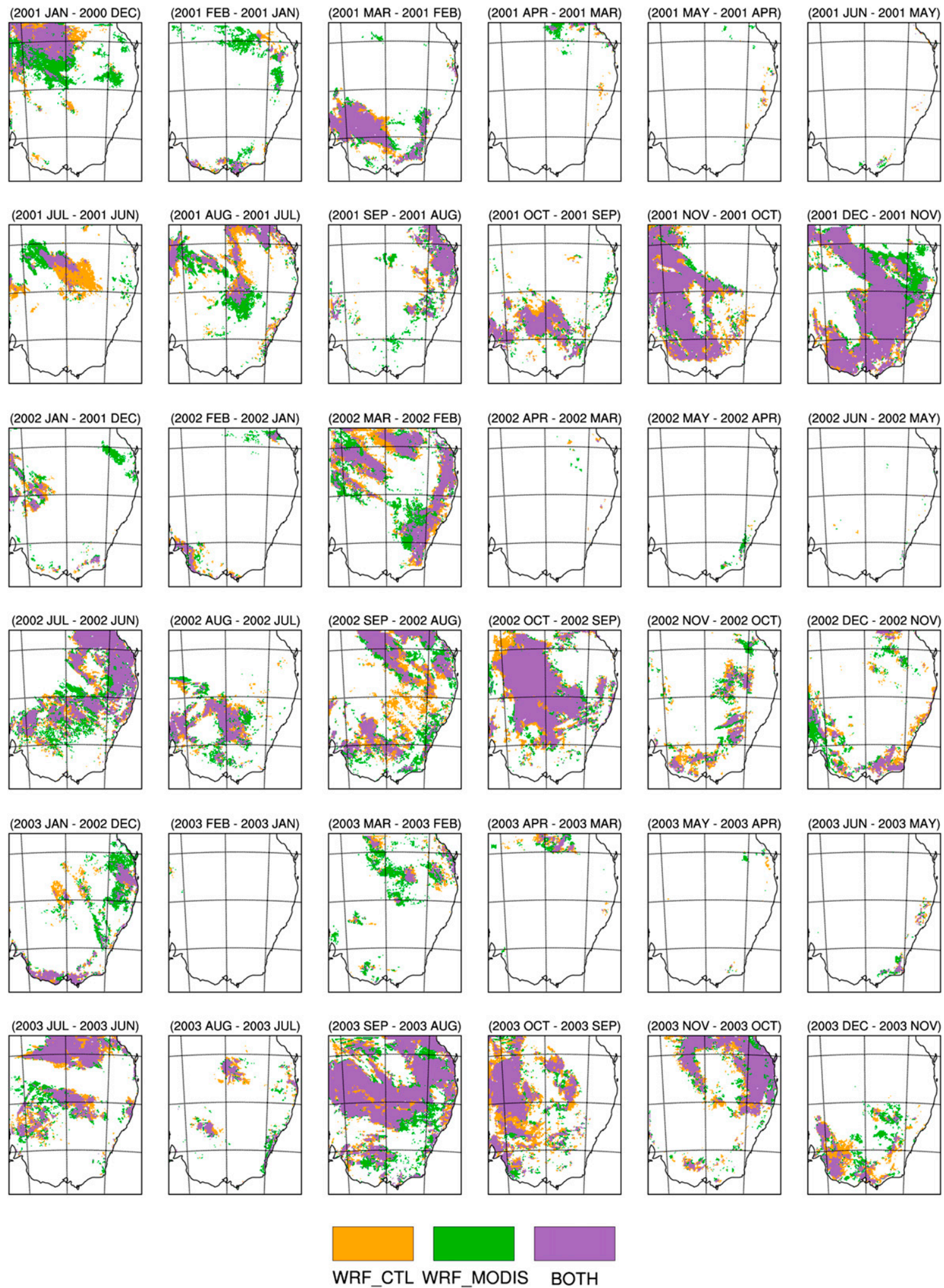

FIG. 11. Distribution of potential fast mechanisms that exist in month by month variations in 2002 and 2003 (orange, green, and purple indicate where the potential fast mechanism exists in WRF_CTL, WRF_MODIS, and both simulations, respectively). 

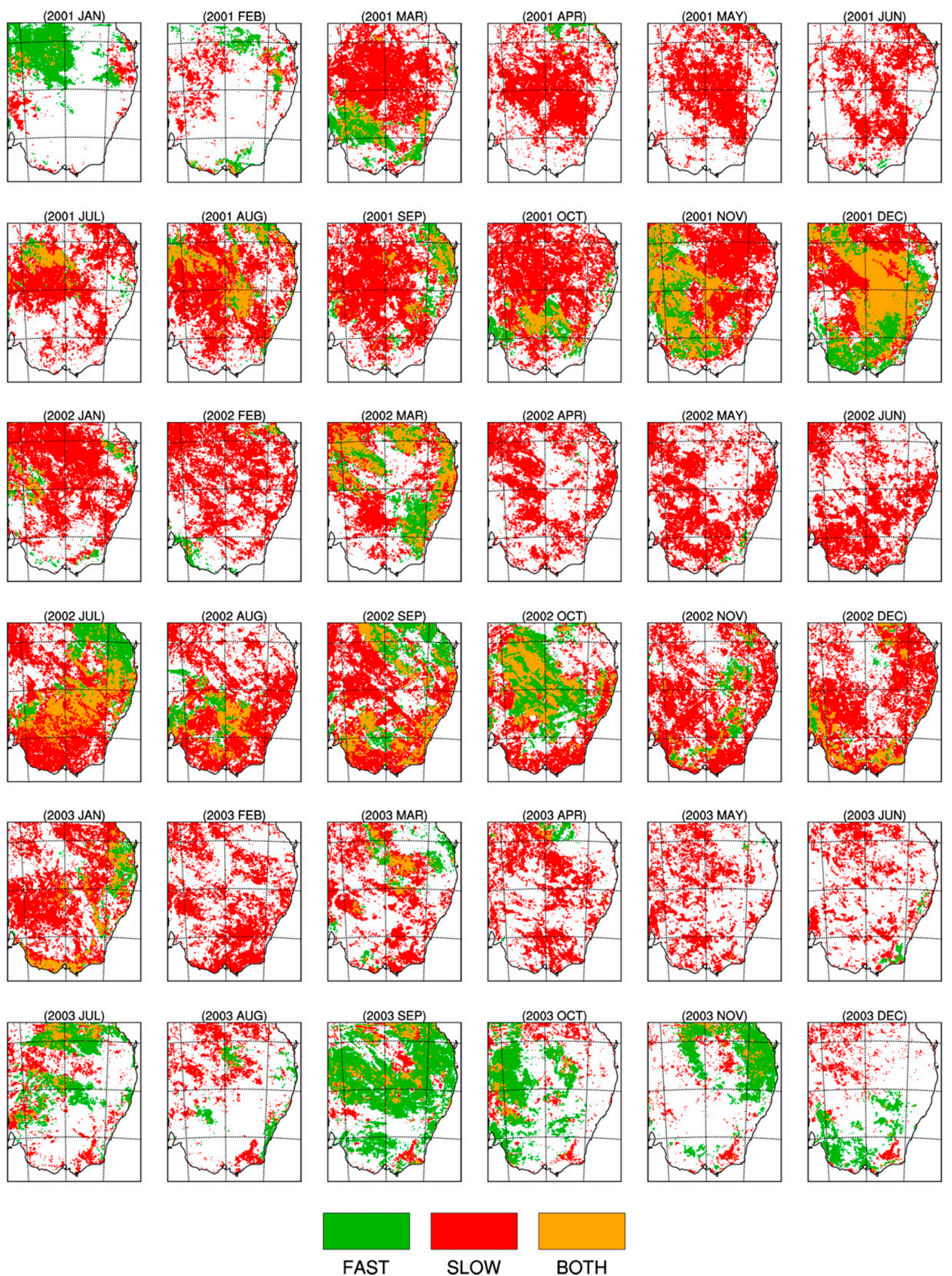

FIG. 12. Distribution of the potential fast and slow mechanisms that exist in monthly and annual variations in the WRF_MODIS simulations in 2002 and 2003 


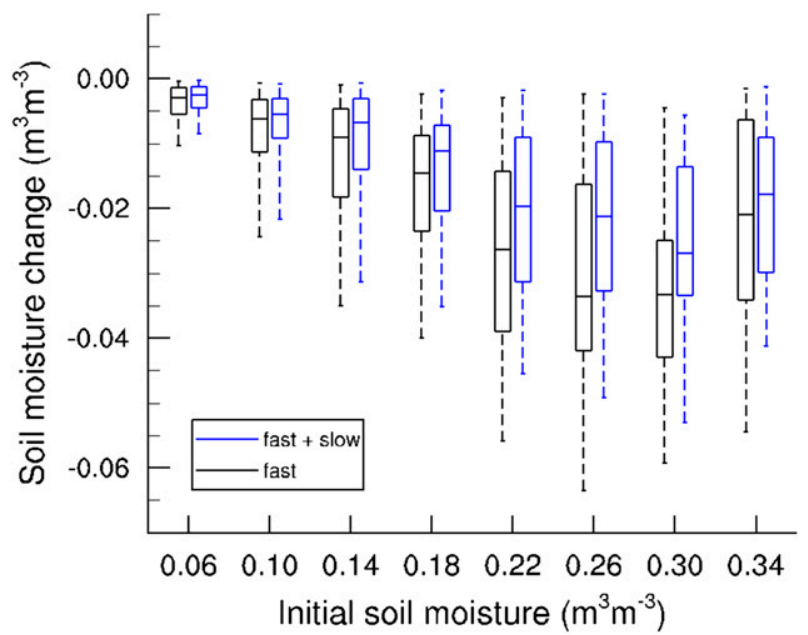

FIG. 13. Box plots showing the monthly change in soil moisture at $100 \mathrm{~cm}$ experienced for a given initial soil moisture. Initial soil moisture values are sorted into bins with width $0.04 \mathrm{~m}^{3} \mathrm{~m}^{-3}$ centered on the values shown. The black plots are derived from grid cells in the WRF_MODIS simulation with only the fast mechanism active, while blue plots are derived from grid cells with both the fast and slow mechanisms active. The center line indicates the median value, the box limits are the 25th and 75 th percentiles, and the dashed lines extend to the 5th and 95th percentiles.

We further explored the land-atmosphere coupling mechanisms by focusing on the drought. In particular, we argue that the drought-related reduction of soil moisture and vegetation fraction have different timescale impacts on local climate change in terms of the 2002 drought. Over short time scales, a fast physical soil moisture-drought feedback is found to be operating and positive owing to the partitioning of energy in the PBL, resulting in a reduction of MSED in the PBL, and leading to less precipitation-consistent with the mechanisms proposed by Eltahir (1998) and Betts and Ball (1998). For the vegetation fraction changes caused by the drought-related persistently low soil moisture, a slower and negative feedback (6-8-month time scale) exists, in which drought-caused vegetation reduction lowers the transpiration and favors preserving water in the soil, slowing down the soil moisture reduction due to the drought.

Results indicate that the slow biological mechanism is active over a larger region than the fast physical mechanism once vegetation changes are evident. Furthermore, the biological mechanism reduces the effectiveness of the fast mechanism. This result suggests that the vegetationsoil moisture-climate interactions are strongly time and region dependent, and the feedback of soil moisture on precipitation is significantly affected by changes in vegetation over interannual time scales.

It should be noted that in this configuration the land surface parameterization does not simulate the influence of soil moisture on surface albedo and therefore structurally excludes the shortwave component of impacts related to surface soil moisture (Zaitchik et al. 2013). Previous work has shown that the fast and positive feedback is strengthened when this soil-moistureinduced albedo change is included (Meng et al. 2014). The implications of this may be that the fast physical feedback is enhanced compared to the slow biological mechanism, as revealed in this study. However, the complexities in the system are such that a future study will be required to test this hypothesis.

The potential effects of vegetation on precipitation suggested by our work are consistent with other investigations. Delire et al. (2004) reported that dynamic vegetation cover tends to enhance the long-term (e.g., decadal or longer) variability of precipitation but dampen it at shorter (e.g., interannual) time scales. Wang et al. (2006) showed that in North American grasslands a negative feedback exists in vegetation-precipitation in the short-term interactions (less than 2 months) and a positive feedback in the long-term interactions (e.g., interannual and longer time scales). Together, these results are complimentary to the present study in that they argue that the nature of vegetation feedbacks can change with various time scales. Here feedbacks related to changes in vegetation outside the arid region are most evident on time scales of at least 6-8 months, while changes in soil moisture, independent of vegetation changes, dominate the shorter time scales. The shorter-time-scale physical feedback can be significantly affected by the slower biological feedback if the drought persists long enough. Drought can be sustained for many years in southeast Australia (Evans et al. 2011); however, these land surfaceatmosphere feedbacks seem to be most important in the onset stage of the drought. What role they play in maintaining the drought once it is established remains to be investigated.

Acknowledgments. This work was funded by the Australian Research Council as part of the Discovery Project DP0772665 and Future Fellowship FT110100576. This work was supported by an award under the Merit Allocation Scheme on the NCI National Facility at the ANU. The work was supported by the Centre of Excellence for Climate System Science, University of New South Wales, Sydney, Australia.

\section{REFERENCES}

Ayliffe, L. K., P. C. Marianelli, K. C. Moriarty, R. T. Wells, M. T. McCulloch, G. E. Mortimer, and J. C. Hellstrom, 1998: $500 \mathrm{ka}$ precipitation record from southeastern Australia: Evidence for interglacial relative aridity. Geology, 26, 147-150, doi:10.1130/ 0091-7613(1998)026<0147:KPRFSA > 2.3.CO;2. 
Betts, A. K., 2009: Land-surface-atmosphere coupling in observations and models. J. Adv. Model. Earth Syst., 1 (3), doi:10.3894/ JAMES.2009.1.4.

— , and J. H. Ball, 1998: FIFE surface climate and site-average dataset 1987-89. J. Atmos. Sci., 55, 1091-1108, doi:10.1175/ 1520-0469(1998)055<1091:FSCASA > 2.0.CO;2.

Cai, W., T. Cowan, P. Briggs, and M. Raupach, 2009: Rising temperature depletes soil moisture and exacerbates severe drought conditions across southeast Australia. Geophys. Res. Lett., 36, L21709, doi:10.1029/2009GL040334.

Case, J., F. LaFontaine, J. Bell, G. Jedlovec, S. Kumar, and C. Peters-Lidard, 2014: A real-time MODIS vegetation product for land surface and numerical weather prediction models. IEEE Trans. Geosci. Remote Sens., 52, 1772-1786, doi:10.1109/TGRS.2013.2255059.

Charney, J., P. Stone, and W. Quirk, 1975: Drought in Sahara: A biogeophysical feedback mechanism. Science, 187, 434-435, doi:10.1126/science.187.4175.434.

Chen, F., and R. Avissar, 1994: The impact of land-surface wetness heterogeneity on mesoscale heat fluxes. J. Appl. Meteor., 33, 13231340, doi:10.1175/1520-0450(1994)033<1323:TIOLSW > 2.0.CO;2.

Cook, B. I., G. B. Bonan, and S. Levis, 2006: Soil moisture feedbacks to precipitation in Southern Africa. J. Climate, 19, 41984206, doi:10.1175/JCLI3856.1.

Delire, C., J. A. Foley, and S. Thompson, 2004: Long-term variability in a coupled atmosphere-biosphere model. J. Climate, 17, 3947-3959, doi:10.1175/1520-0442(2004)017<3947:LVIACA > 2.0.CO;2.

Eltahir, E. A. B., 1998: A soil moisture rainfall feedback mechanism: 1 . Theory and observations. Water Resour. Res., 34, 765776, doi:10.1029/97WR03499.

Evans, J. P., and M. F. McCabe, 2010: Regional climate simulation over Australia's Murray-Darling basin: A multitemporal assessment. J. Geophys. Res., 115, D14114, doi:10.1029/2010JD013816.

_ , and S. Westra, 2012: Investigating the mechanisms of diurnal rainfall variability using a regional climate model. J. Climate, 25, 7232-7247, doi:10.1175/JCLI-D-11-00616.1.

— , and M. F. McCabe, 2013: Effect of model resolution on a regional climate model simulation over southeast Australia. Climate Res., 56, 131-145, doi:10.3354/cr01151.

- A. J. Pitman, and F. T. Cruz, 2011: Coupled atmospheric and land surface dynamics over southeast Australia: A review, analysis and identification of future research priorities. Int. J. Climatol., 31, 1758-1772, doi:10.1002/joc.2206.

— M. Ekström, and F. Ji, 2012: Evaluating the performance of a WRF physics ensemble over South-East Australia. Climate Dyn., 39, 1241-1258, doi:10.1007/s00382-011-1244-5.

Findell, K. L., and E. A. B. Eltahir, 2003a: Atmospheric controls on soil moisture-boundary layer interactions. Part I: Framework development. J. Hydrometeor., 4, 552-569, doi:10.1175/ 1525-7541(2003)004<0552:ACOSML>2.0.CO;2.

- , and $-2003 \mathrm{~b}$ : Atmospheric controls on soil moistureboundary layer interactions. Part II: Feedbacks within the continental United States. J. Hydrometeor., 4, 570-583, doi:10.1175/ 1525-7541(2003)004<0570:ACOSML > 2.0.CO;2.

Fu, G., N. Viney, S. Charles, and J. Liu, 2010: Long-term temporal variation of extreme rainfall events in Australia: 1910-2006. J. Hydrometeor., 11, 950-965, doi:10.1175/2010JHM1204.1.

Guerschman, J., M. Hill, L. Renzullo, D. Barrett, A. Marks, and E. Botha, 2009: Estimating fractional cover of photosynthetic vegetation, non-photosynthetic vegetation and bare soil in the Australian tropical savanna region upscaling the EO-1 Hyperion and MODIS sensors. Remote Sens. Environ., 113, 928945, doi:10.1016/j.rse.2009.01.006.
Gutman, G., and A. Ignatov, 1998: The derivation of the green vegetation fraction from NOAA/AVHRR data for use in numerical weather prediction models. Int. J. Remote Sens., 19, 1533-1543, doi: $10.1080 / 014311698215333$.

Jones, D. A., W. Wang, and R. Fawcett, 2009: High-quality spatial climate data-sets for Australia. Aust. Meteor. Mag., 58, 233 248.

Koster, R. D., and Coauthors, 2006: GLACE: The Global LandAtmosphere Coupling Experiment. Part I: Overview. J. Hydrometeor., 7, 590-610, doi:10.1175/JHM510.1.

Liu, Y. Y., A. I. J. M. van Dijk, M. F. McCabe, J. P. Evans, and R. A. M. de Jeu, 2013: Global vegetation biomass change (1988-2008) and attribution to environmental and human drivers. Global Ecol. Biogeogr., 22, 692-705, doi:10.1111/ geb.12024.

Liu, Z., M. Notaro, J. Kutzbach, and N. Liu, 2006: Assessing global vegetation-climate feedbacks from observations. J. Climate, 19, 787-814, doi:10.1175/JCLI3658.1.

Matsui, T., V. Lakshmi, and E. E. Small, 2005: The effects of satellite-derived vegetation cover variability on simulated land-atmosphere interactions in the NAMS. J. Climate, 18, 21-40, doi:10.1175/JCLI3254.1.

Meng, X. H., J. P. Evans, and M. F. McCabe, 2014: The influence of inter-annually varying albedo on regional climate and drought. Climate Dyn., doi:10.1007/s00382-013-1790-0, in press.

Murphy, B., and B. Timbal, 2008: A review of recent climate variability and climate change in southeastern Australia. Int. J. Climatol., 28, 859-879, doi:10.1002/joc.1627.

Pielke, R. A., G. A. Dalu, J. S. Snook, T. J. Lee, and T. G. F. Kittel, 1991: Nonlinear influence of mesoscale land-use on weather and climate. J. Climate, 4, 1053-1069, doi:10.1175/ 1520-0442(1991)004<1053:NIOMLU>2.0.CO;2.

—-, R. Avissar, M. Raupach, A. J. Dolman, X. B. Zeng, and A. S. Denning, 1998: Interactions between the atmosphere and terrestrial ecosystems: Influence on weather and climate. Global Change Biol., 4, 461-475, doi:10.1046/ j.1365-2486.1998.t01-1-00176.x.

Potter, N. J., F. H. S. Chiew, and A. J. Frost, 2010: An assessment of the severity of recent reductions in rainfall and runoff in the Murray-Darling Basin. J. Hydrol., 381, 52-64, doi:10.1016/ j.jhydrol.2009.11.025.

Risbey, J. S., M. J. Pook, P. C. McIntosh, M. C. Wheeler, and H. H. Hendon, 2009: On the remote drivers of rainfall variability in Australia. Mon. Wea. Rev., 137, 3233-3253, doi:10.1175/ 2009MWR2861.1.

Seneviratne, S. I., T. Corti, E. L. Davin, M. Hirschi, E. B. Jaeger, I. Lehner, B. Orlowsky, and A. J. Teuling, 2010: Investigating soil moisture-climate interactions in a changing climate: A review. Earth Sci. Rev., 99, 125-161, doi:10.1016/j.earscirev.2010.02.004.

Sharples, J. J., G. A. Mills, R. H. D. Mcrae, and R. O. Weber, 2010: Foehn-like winds and elevated fire danger conditions in southeastern Australia. J. Appl. Meteor. Climatol., 49, 1067-1095, doi:10.1175/2010JAMC2219.1.

Skamarock, W. C., and Coauthors, 2008: A description of the Advanced Research WRF version 3. NCAR Tech. Note NCAR/TN-475+STR, 113 pp. [Available online at http:// www.mmm.ucar.edu/wrf/users/docs/arw_v3.pdf.]

Small, E. E., and S. A. Kurc, 2003: Tight coupling between soil moisture and the surface radiation budget in semiarid environments: Implications for land-atmosphere interactions. Water Resour. Res., 39, 1278, doi:10.1029/2002WR001297.

Teng, J., F. H. S. Chiew, B. Timbal, Y. Wang, J. Vaze, and B. Wang, 2012: Assessment of an analogue downscaling method for 
modelling climate change impacts on runoff. J. Hydrol., 472473, 111-125, doi:10.1016/j.jhydrol.2012.09.024.

Ummenhofer, C. C., M. H. England, P. C. Mclntosh, G. A. Meyers, M. J. Pook, J. S. Risbey, A. S. Gupta, and A. S. Taschetto, 2009: What causes southeast Australia's worst droughts? Geophys. Res. Lett., 36, L04706, doi:10.1029/2008GL036801.

_ and Coauthors, 2011: Indian and Pacific Ocean influences on southeast Australian drought and soil moisture. J. Climate, 24, 1313-1336, doi:10.1175/2010JCLI3475.1.

van Dijk, A. I. J. M., H. E. Beck, R. S. Crosbie, R. A. M. De Jeu, Y. Y. Liu, G. M. Podger, B. Timbal, and N. R. Viney, 2013: The Millennium Drought in southeast Australia (2001-2009): Natural and human causes and implications for water resources, ecosystems, economy, and society. Water Resour. Res., 49, 1040-1057, doi:10.1002/wrcr.20123.

Wang, L., P. D’Odorico, J. P. Evans, D. J. Eldridge, M. F. Mccabe, K. K. Caylor, and E. G. King, 2012: Dryland ecohydrology and climate change: Critical issues and technical advances. Hydrol. Earth Syst. Sci., 16, 2585-2603, doi:10.5194/hess-16-2585-2012.

Wang, W., B. T. Anderson, N. Phillips, R. K. Kaufmann, C. Potter, and R. B. Myneni, 2006: Feedbacks of vegetation on summertime climate variability over the North American grasslands. Part I: Statistical analysis. Earth Interact., 10, doi:10.1175/ EI196.1.
Wei, Y., J. Langford, I. R. Willett, S. Barlow, and C. Lyle, 2011: Is irrigated agriculture in the Murray Darling Basin well prepared to deal with reductions in water availability? Global Environ. Change, 21, 906-916, doi:10.1016/j.gloenvcha.2011.04.004.

Xue, Y., F. De Sales, R. Vasic, C. R. Mechoso, A. Arakawa, and S. Prince, 2010: Global and seasonal assessment of interactions between climate and vegetation biophysical processes: A GCM study with different land-vegetation representations. J. Climate, 23, 1411-1433, doi:10.1175/2009JCLI3054.1.

Zaitchik, B. F., J. P. Evans, and R. B. Smith, 2005: MODIS-derived boundary conditions for a mesoscale climate model: Application to irrigated agriculture in the Euphrates Basin. Mon. Wea. Rev., 133, 1727-1743, doi:10.1175/MWR2947.1.

, R. A. Geerken, and R. B. Smith, 2007: Climate and vegetation in the Middle East: Interannual variability and drought feedbacks. J. Climate, 20, 3924-3941, doi:10.1175/JCLI4223.1.

_ J. A. Santanello, S. V. Kumar, and C. D. Peters-Lidard, 2013: Representation of soil moisture feedbacks during drought in NASA Unified WRF (NU-WRF). J. Hydrometeor., 14, 360367, doi:10.1175/JHM-D-12-069.1.

Zeng, N., and J. D. Neelin, 2000: The role of vegetation-climate interaction and interannual variability in shaping the African savanna. J. Climate, 13, 2665-2670, doi:10.1175/ 1520-0442(2000)013<2665:TROVCI > 2.0.CO;2. 